\title{
Commentary on "New Frontiers or the Treatment of Interstitial Cystitis/Bladder Pain Syndrome-Focused on Stem Cells, Platelet-Rich Plasma, and Low-Energy Shock Wave"
}

\author{
Aram Kim \\ Department of Urology, KonKuk University Medical Center, KonKuk University School of Medicine, Seoul, Korea
}

To the editor,

I read the recently published review paper by Dr. Yao-Chi Chuang et al. titled "New Frontiers or the Treatment of Interstitial Cystitis/Bladder Pain Syndrome - Focused on Stem Cells, Platelet-Rich Plasma, and Low-Energy Shock Wave" with great interest. The authors introduced stem cell therapy, platelet-rich plasma, and low-energy shock wave as new alternative treatment strategies for interstitial cystitis/bladder pain syndrome (IC/BPS) [1]. This review is very valuable because conventional therapies for IC/BPS have shown limited outcomes.

Various treatment options, including behavioral therapy, oral pharmacotherapy, and intravesical instillation have been suggested for the treatment of IC/BPS, although none of them provide a definite cure for the disease. Patients for whom conservative and oral medication treatments produce insufficient effects require endoscopic treatment, such as transurethral resection and cauterization (TUR-C) of the Hunner lesions and hydrodistension of the bladder. However, TUR-C leads to symptom recurrence and hydrodistension has a short duration of efficacy $[2,3]$. Therefore, clinicians and scientists are interested in developing new treatment options.

It is important to note that the development of new options should be focused on the pathophysiology of IC/BPS, as mentioned in the present review paper. Two critical aspects required of new treatment tools include anti-inflammatory and regenerative effects. Therefore, many clinical scientists have researched the application of stem cell therapy for IC/BPS. Stem cell thera- py is an ideal candidate for anti-inflammation and tissue regeneration, and interest in its clinical potential has dramatically increased over the last 3 decades [4]. In International Neurourology Journal, there is a good example of the application of stem cell therapy for IC/BPS. Lee et al. [5] demonstrated the therapeutic effect of human embryonic stem cell-derived multipotent mesenchymal stem cells on ketamine-induced cystitis in rats.

Many published preclinical studies have shown promising outcomes; however, there have been no human clinical trials to date. There are several reasons for this. First, there are safety concerns regarding the application of stem cell therapy in human patients. Even though the outcomes of preclinical studies are promising, the issue of malignant tissue formation in embryonic stem cell-derived multipotent and induced pluripotent stem cells (iPSC) remains to be solved. Second, researchers do not know the mode of action of stem cells. Initially, the therapeutic applications of mesenchymal stem cells were investigated to replace injured cells based on their differentiation potential. However, less than $1 \%$ of the transplanted stem cells could reach the target tissue in the treatment of myocardial infarction [6]. Due to the lack of a reliable strategy to address the limitations of stem cell therapy, the use of exosomes from stem cells warrants consideration.

Exosomes have been proposed to act as the main mediators of the paracrine effects of mesenchymal stem cells by fractioning the extracellular components. Thus, a population of small
Corresponding author: Aram Kim (iD https://orcid.org/0000-0002-2055-2262 Department of Urology, KonKuk University Medical Center, KonKuk University School of Medicine, 120-2 Neungdong-ro, Gwangjin-gu, Seoul 05030, Korea E-mail: arkim@kuh.ac.kr

Submitted: October 12, 2020 / Accepted after revision: November 17, 2020 (i) (5) This is an Open Access article distributed under the terms of the Creative Commons Attribution Non-Commercial License (https://creativecommons.org/licenses/by-nc/4.0/) which permits unrestricted non-commercial use, distribution, and reproduction in any medium, provided the original work is properly cited. 
vesicles that are up to $150 \mathrm{~nm}$, positive for CD9, CD81, and Alix, and able to mediate the regenerative and anti-inflammatory effects of mesenchymal stem cells in a series of pathologies was identified. Exosomes have been used for both in vitro and in vivo studies and have proved to be efficient for ameliorating pathological conditions, such as neurological injury, kidney injury, diabetes, myocardial infarction and wound healing [7]. Moreover, recent discoveries have shown that mesenchymal stem cells-derived exosomes prevent the progression of degenerative changes [8]. Unlike autologous iPSC transplantation, no teratomas formation has been observed in groups receiving exosomes. As a result, the clinical applications of mesenchymal stem cell-derived exosomes are advantageous over those of mesenchymal stem cell-based therapy, as they have lower immunogenicity, the capacity to cross biological barriers, and fewer safety concerns; stem cell therapy presents the possibility of tumor generation, whereas exosomes do not [9].

Research on the application of exosomes in medicine is in its early stages; however, further studies on this technique could help scientists and clinicians overcome the limitations of stem cell therapy. Research on new innovative treatments, such as that in the present review paper, is necessary in order to move forward and provide better outcomes for patients with IC/BPS in the future.

"If you can't fly then run, if you can't run then walk, if you can't walk then crawl, but whatever you do, you have to keep moving forward." - Dr. Martin Luther King Junior.

- Conflict of Interest: No potential conflict of interest relevant to this article was reported.

\section{REFERENCES}

1. Lin CC, Huang YC, Lee WC, Chuang YC. New Frontiers or the treatment of interstitial cystitis/bladder pain syndrome-focused on stem cells, platelet-rich plasma, and low-energy shock wave. Int Neurourol J 2020;24:211-21.

2. Hanno PM, Erickson D, Moldwin R, Faraday MM, et al. Diagnosis and treatment of interstitial cystitis/bladder pain syndrome: AUA guideline amendment. J Urol 2015;193:1545-53.

3. Al'-Shukri SK, Kużmin IV, Slesarevskaya MN, Ignashov YA. Bladder hydrodistension in treating patients with interstytial cystitis/ bladder pain syndrome. Urologiia 2018;(1):26-9.

4. Klimczak A, Kozlowska U. Mesenchymal stromal cells and tissuespecific progenitor cells: their role in tissue homeostasis. Stem Cells Int 2016;2016:4285215.

5. Lee SW, Ryu CM, Shin JH, Choi D, Kim A, Yu HY, et al. The therapeutic effect of human embryonic stem cell-derived multipotent mesenchymal stem cells on chemical-induced cystitis in rats. Int Neurourol J 2018;22:34-45.

6. Barbash IM, Chouraqui P, Baron J, Feinberg MS, Etzion S, Tessone A, et al. Systemic delivery of bone marrow-derived mesenchymal stem cells to the infarcted myocardium: feasibility, cell migration, and body distribution. Circulation 2003;108:863-8.

7. Rosca AM, Tutuianu R, Titorencu ID. Mesenchymal stromal cells derived exosomes as tools for chronic wound healing therapy. Rom J Morphol Embryol 2018;59:655-62.

8. Liao ZW, Luo R, Li G, Song Y, Zhan S, Zhao K, et al. Exosomes from mesenchymal stem cells modulate endoplasmic reticulum stress to protect against nucleus pulposus cell death and ameliorate intervertebral disc degeneration in vivo. Theranostics 2019;9:4084100.

9. Woo CH, Kim HK, Jung GY, Jung YJ, Lee KS, Yun YE, et al. Small extracellular vesicles from human adipose-derived stem cells attenuate cartilage degeneration. J Extracell Vesicles 2020;9:1735249. 